\title{
Educação de infância em Portugal: discursos, projetos e práticas (1834 -1974)
}

Early Childhood Education in Portugal: Discourses, Projects and Practices (1834 -1974)

Educación de la primera infancia en Portugal: discursos, proyectos y prácticas (1834-1974)

António Gomes-Ferreira* iD orcid.org/0000-0002-3281-6819

Luis Mota** iD orcid.org/0000-0003-4014-9590

Carla Vilhena*** iD orcid.org/0000-0002-5524-5174

Para citar este artículo: Gomes-Ferreira, A., Mota, L. y Vilhena, C. (2021). Educação de infância em Portugal: discursos, projetos e práticas (1834 -1974). Revista Colombiana de Educación, 1(82), $241-262$. https://doi.org/ 10.17227/rce.num82-10812

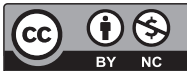

Recibido: 29/11/2019

Evaluado: 21/07/2020

$19 / 08 / 2020$

$08 / 08 / 2020$

* Doutoramento em Ciências da Educação, pela Universidade de Coimbra. Faculdade de Psicologia e de Ciências da Educação da Universidade de Coimbra, Portugal. Correo: antonio@fpce.uc.pt

** Doutoramento em História da Cultura, pela Universidade de Coimbra. Instituto Politécnico de Coimbra Escola Superior de Educação/ Grupo de Políticas e Organizações Educativas e Dinâmicas Educacionais, Centro de Estudos Interdisciplinares do Século xx, da Universidade de Coimbra, Portugal. Correo: mudamseostempos@gmail.com

*** Doutoramento em Ciências da Educação, pela Universidade Nova de Lisboa. Faculdade de Ciências Humanas e Sociais da Universidade do Algarve/ Grupo de Políticas e Organizações Educativas e Dinâmicas Educacionais, Centro de Estudos Interdisciplinares do Século xx, da Universidade de Coimbra, Portugal. Correo: cvilhena@ualg.pt 


\section{Resumo}

O presente trabalho constitui um bosquejo dos caminhos da educação de infância em Portugal, ao longo de 150 anos, entre 1834 e o fim do Estado Novo, em abril de 1974. Visa produzir uma leitura compreensiva da evolução do pensamento e ação sobre o cuidar e educar das crianças na primeira infância. Centra-se na análise do discurso oficial, no pensamento e debate pedagógico, bem como na sua concretização. O corpus documental é constituído pela produção legislativa e por uma coletânea de textos sobre a educação infantil, compilados na imprensa de educação e ensino. Estas fontes oferecem uma aproximação às ideias, propostas, projetos e iniciativas que, seja por via do Estado ou corporizadas pela sociedade civil, se foram esboçando, estiilando ou concretizando no longo período de construção da modernidade em Portugal. Ao Sujeitas ao método crítico e à análise de conteúdo, o seu escrutínio permitiu observar que a difusão das ideias e a concretização de políticas e instituições educativas destinadas a esta faixa etária, profundamente marcadas pelas condições materiais e simbólicas da formação social portuguesa, foi morosa e eivada de dificuldades. Em larga medida, expressão do locus nacional, traduziu uma apropriação de teorias e práticas internacionais.

\section{Palavras-chave}

Criança; infância; educação de infância; jardim de infância; política educativa

\section{Keywords}

Child; childhood; early childhood education; nursery school; educational policy

\begin{abstract}
This paper is a summary of the paths in early childhood education in Portugal, during 1834 and the end of the Estado Novo, in April of 1974, proposing a comprehensive reading of the evolution of thinking and action on the care and education of children in early childhood. This text also focuses on the analysis of official discourse, thought and pedagogical debate, as well as its realization. The documentary corpus used in this article, consists of the legislative production and a collection of texts on early childhood education, compiled in the education and teaching press. Those sources allow us to analyze ideas, proposals, projects and initiatives that, either through the State or embodied by civil society, were marking the long period of construction of modernity in Portugal. The documentary body was subjected to the critical method and content analysis, that showed that the diffusion of ideas and the implementation of educational policies and institutions was slow and accompanied by difficulties. Slow process that was rooted in the material and symbolic conditions of portuguese society. To a large extent, an expression of the nationa locus, translated an appropriation of international theories and practices.
\end{abstract}

\section{Resumen}

Este documento es un resumen de los caminos de la educación de la primera infancia en Portugal, durante 150 años, entre 1834 y el final del Estado Novo, en abril de 1974. Su objetivo es producir una lectura de la evolución del pensamiento y la acción sobre el cuidado y la educación de los niños. Se centra en el análisis del discurso oficial, el pensamiento y el debate pedagógico, así como su realización. El corpus documental consiste en la producción legislativa y una colección de textos sobre educación de la primera infancia, compilados en la prensa pedagógica. Estas fuentes ofrecen una aproximación a las ideas, propuestas, proyectos e iniciativas que, ya sea a través del estado o encarnadas por la sociedad civil, se han esbozado, estirado o materializado en el largo período de construcción de la modernidad en Portugal. Al someterlas al método crítico y al análisis de contenido, su escrutinio nos permitió observar que la difusión de ideas y la implementación de políticas e instituciones educativas para este grupo de edad, profundamente marcada por las condiciones materiales y simbólicas de la formación social portuguesa, fue lenta y marcada por dificultades. En gran medida, la expresión del locus nacional tradujo una apropiación de teorías y prácticas internacionales.

\section{Palabras clave}

Niño; infancia; educación de la primera infancia; escuela de párvulos; política de la educación 


\section{Introdução}

Indagar sobre o cuidar e o educar das crianças nos seus primeiros anos, em Portugal, não pode deixar de ter presente que esse debate se compaginou com o ocorrido nos países europeus, inscrevendo-se nos mesmos padrões e mobilizando um conjunto de ideias transnacionais. Em consonância, qualquer demanda sobre a temática não pode, por isso mesmo, deixar de ter presente uma perspetiva mais abrangente, mesmo quando a preocupação central é a realidade nacional (Ferreira et al., 2019).

A discussão em redor dos cuidados para com as crianças e das atitudes perante a infância filiam-se no devir histórico, pelo que exigem que se dê a devida atenção às condições materiais e culturais de cada época e de cada formação social, única forma de apreciar criticamente, sem incorrer no "pecado" do anacronismo, a razoabilidade e coerência (ou a falta dela) de certas práticas que, eventualmente, hoje nos suscitariam estranheza e até rejeição (Ferreira et al., 2019).

Nesta perspetiva, releve-se que as transformações económicas, sociais e políticas têm, e tiveram no passado, consequências mais ou menos impactantes tanto no domínio cultural como educacional. As alterações ocorridas, nomeadamente, a intensificação gradual do comércio, a par de uma crescente complexificação administrativa, colocaram na agenda novas competências para aqueloutros destinados a envolverem-se na gestão dos assuntos burocrático-administrativos. Com o desenvolvimento da formação da burguesia e o maior reconhecimento do valor da educação, inicia-se um processo de escolarização do espaço europeu. Caldeadas no humanismo e nas reformas religiosas —inicialmente, entre os Estados protestantes, mas igualmente na Europa católica-, difundem-se, no espaço europeu, ideias sobre a educação das crianças (Ferreira, 1988; Ferreira e Pereira, 1987) e propostas educativas ou didáticas, denunciando uma renovação da atenção com a infância (Ferreira et al., 2019).

Ao longo das centúrias de Setecentos e Oitocentos assiste-se à difusão da ideia de que a criação e educação das crianças deveria ter subjacente uma racionalidade, isto é, de que não deveria ser obra do acaso, ideia que perdurou e se desenvolveu até aos nossos dias. A emergência desta conceção é acompanhada, no século XVIII, pela descoberta da criança em idade pré-escolar como um ser inteligente, cuja educação não deveria ser negligenciada. Para essa descoberta da segunda infância contribuíram médicos e pedagogos que chamaram a atenção para as necessidades educativas das primeiras idades e, desde finais do século xIX, os peritos psi (Beatty, Cahan e Grant, 2006; Brehony, 2009; Ferreira, 2000; Ferreira e Gondra, 2006; Luc, 1997). 
Esta nova atenção aos primeiros anos de vida teve reflexo nos discursos e na ação política que tinham como objeto a infância. Num momento em que, devido à crescente escolarização das populações, se assistiu à construção de uma nova imagem da infância, a de criança aluno (Hendrick, 1997; Hofstetter, 2012). A preocupação com a segurança e com as necessidades futuras do Estado contribuíram para o desenvolvimento da ideia de criança da nação, que estava associada à perceção da infância como um período especialmente apto à modelação em que se construía o futuro dos indivíduos e, consequentemente, das nações (Cunningham, 1995; Hendrick, 1997). Sendo um período especialmente propenso à ação educativa, e dada a importância social que a educação assumia aos olhos das elites políticas e intelectuais, a criação e educação das crianças transformou-se num assunto de interesse público, deixando de ser considerado como uma questão do foro privado e da exclusiva responsabilidade das famílias (Brehony, 2009; White, 2002). É neste contexto que foram criadas as primeiras instituições de educação de infância, cujas principais finalidades seriam dispensar os cuidados necessários à sobrevivência e à manutenção da saúde e, simultaneamente, prover à educação moral e intelectual das crianças (Beatty, 1995; Luc, 1997; Wollons, 2000).

Embora possamos falar da existência de algumas iniciativas no âmbito da proteção e educação da infância antes do século xIX, de que a mais conhecida é a école des plus jeunes, criada em 1769 pelo pastor protestante Jean Oberlin, é na centúria de Oitocentos que se avançou deliberada e definitivamente para a criação de estabelecimentos educativos que tinham como destinatários as crianças em idade pré-escolar. São exemplos desta realidade as infant school inglesas, as salles d'asile francesas, transformadas, no final do século xIx, em écoles maternelles ou no kindergarten de Froebel, na Alemanha, a que se juntam, no século xx, as Casa dei Bambini, criadas por Maria Montessori, referindo apenas algumas das mais conhecidas e cuja influência não só se estendeu a outras regiões do globo, como perdurou até aos nossos dias (Dombkowski, 2001; Luc, 1997; Read, 2013; Whitescarver e Cossentino, 2008).

É importante sublinhar, ainda assim, que se tratou de um processo lento e desigual que resultou de acentuados contrastes regionais (e locais), com base em profundas assimetrias socioeconómicas e em face de diversas composições sociais e culturais de que resultaram diferenciadas apropriações das ideias sobre a educação das crianças e distintos posicionamentos sobre a assunção da infância (Ferreira et al., 2019).

No presente trabalho procurou-se esboçar os caminhos percorridos pela educação de infância em Portugal, centrando a análise em três dimensões: o discurso oficial, o debate pedagógico e as práticas. Nesta perspetiva, recorreu-se à legislação e outra documentação oficial dimanada 
pela tutela, mobilizaram-se outras publicações sobre o tema em apreço (e.g., manuais), e, muito especialmente, convocaram-se um conjunto de textos publicados em revistas de educação e ensino - e.g., Froebel (1882-1885), Alma Feminina (1914-1946), Educação Social (1924-1927); A Saúde (1931-1943), Os Nossos Filhos (1942-1964), A Criança Portuguesa (1942-1963)—, um dos veículos (privilegiado) de difusão das ideias dominantes sobre a educação de infância (Boto, 2001; Nery, 2006), e que, simultaneamente, permitiu aceder a relatos de experiências concretas ocorridos no período em análise.

De acordo com o exposto, as condições económicas, sociais, políticas e culturais configuram, de forma indelével, o desenvolvimento da educação das crianças e a assunção da infância em Portugal, conformando as dimensões de análise - discurso oficial, debate pedagógico e práticas-, a sua visibilidade e o grau de interpenetração. A narrativa percorre dois grandes períodos, o Portugal liberal e o do Estado Novo. A aproximação ao tempo do liberalismo subdivide-se, por sua vez, em dois subperíodos: no primeiro, a análise centra-se no tempo que medeia entre as primeiras iniciativas e o início do processo de integração no sistema educativo e que corresponde, lato senso, à vigência da monarquia constitucional; no segundo, correspondente ao regime republicano, caracteriza-se como um momento de construção retórica da escolarização da infância. O quase meio século de existência do Estado Novo surge dividido em duas etapas distintas: inicialmente, as políticas para a educação da infância surgem moldadas pela ideologia da maternidade contaminando, como se observará, as dimensões analíticas; enquanto a partir das décadas de cinquenta/sessenta, muito em função das mudanças invisíveis (Rosas, 1994) ocorridas na sociedade portuguesa, a educação das crianças e a perceção da infância são atravessadas pelas preocupações com a formação de recursos humanos para o desenvolvimento económico, a expansão da escolaridade e o planeamento educativo (Ferreira et al., 2019).

\section{A emergência da educação de infância formal $(1834-1910)$}

As primeiras iniciativas com o criar e cuidar das crianças em Portugal têm a sua epígrafe nas "Misericórdias", criadas pela rainha D. Leonor (1485), que cumpriam preocupações de natureza social, circunscrevendo o seu interesse às crianças desfavorecidas ou sem família. Iniciativa acompanhada por uma das primeiras coletâneas de leis (Ordenações) que cometiam ao poder público a proteção de órfãos e abandonados (Ordenações Afonsinas, s. d.). De resto, é incontrastável e significativo que, até final do século xıx, o abandono de crianças —recém-nascidas 
ou de tenra idade - constituía uma práxis difundida e admitida, o que convoca as Casas da Roda ou os orfanatos, com caráter assistencial e, posteriormente, em linha com as práticas no continente europeu, os Asilos de Infância (Ferreira et al., 2019).

Em 1834, por iniciativa da Sociedade das Casas de Asilo da Infância Desvalida e com patrocínio do rei D. Pedro iv, são criadas as Casas de Asilo da Infância Desvalida, cuja finalidade era acolher e educar crianças com idades compreendidas entre os 2 e os 7 anos, durante o período de trabalho das mães. Destinadas a crianças provenientes de famílias pobres, tinham um caráter predominantemente assistencial, embora não se descurasse a dimensão educativa, explicitando-se a preocupação com o desenvolvimento das faculdades das crianças (Vasconcelos, 1853).

Além de constituírem uma novidade em termos de assistência, pois destinavam-se ao acolhimento de crianças pobres com família, e não de órfãos ou expostos, como as instituições que até aí existiam (Lopes, 1993), as salas de asilo constituem-se como um espaço específico para o acolhimento das crianças mais novas, diferente da escola primária, antecipando o movimento pedagógico que estaria na origem da criação de escolas infantis e jardins de infância (Ferreira e Gondra, 2006).

Cingindo-se inicialmente a Lisboa, rapidamente são criadas Casa de Asylo noutras localidades do país (e.g. Funchal, Porto, Coimbra, Viana do Castelo), o que atesta, por um lado, a preocupação com a solução de um problema específico, o destino das crianças mais pequenas cujas mães necessitavam de trabalhar, e, por outro, seguindo a lógica do filantropismo cristão, com a sua conservação, moralização e educação.

A dimensão educativa, aparentemente, estende-se ao Estado, primeiro com a reforma de António da Costa Sousa Macedo, em 1870, ao abrir a frequência escolar às crianças a partir dos 5 anos de idade e, oito anos mais tarde, com a legislação de António Rodrigues Sampaio, ao criarem-se asilos de educação destinados a crianças com idades compreendidas entre os 3 e os 6 anos, da responsabilidade das Juntas Gerais de Distrito e as Câmaras Municipais, de resto, estabelecimentos que acabariam por representar as escolas das "primeiras letras".

A produção legislativa foi acompanhada da valorização da função educativa das instituições, contudo os resultados foram (menos que) insignificantes. A designação de asilo de educação continuou a prevalecer sobre a de jardim de infância até 1880, momento em que o Estado prevê a sua criação, seguindo o modelo froebeliano e delineia a equiparação das Casas de Asilo a jardins (Vasconcelos, 2004). Ainda assim, preocupação de pedagogos e políticos, o ensino infantil enfrentava a incapacidade do Estado em concretizar um projeto significativo no âmbito do sistema educativo, sendo sucessivamente adiado. 
A década de oitenta mostrar-se-ia decisiva para a criação do primeiro jardim de infância em Portugal com o alinhamento do discurso político — documentação oficial e produção legislativa — com a vontade política, disponibilizando-se o governo a atribuir subsídio - a consignar em sede de orçamento geral do Estado- para a abertura de jardins de infância para a educação de crianças de 3 a 6 anos de idade pelo método Froebel, e com a capacidade de iniciativa, presente no contributo decisivo de Teófilo Ferreira (1840-1893), diretor da Escola Normal e responsável pelo pelouro da instrução, na Câmara Municipal de Lisboa, desde janeiro de 1882. No ano do centenário do nascimento de Friedrich Froebel foi inaugurado em Lisboa, no jardim da Estrela, o primeiro jardim de infância público, influenciado pelo método froebeliano, onde se espectava habilitar recursos humanos para os jardins que se planeara criar (Ferreira, 1882).

Na década seguinte, a legislação de 1894 prevê a criação de jardins de infância em Lisboa, no Porto e em outras povoações importantes. No lustro imediato, o Regulamento do Ensino Primário (1896), em que a educação de infância é integrada no sistema educativo, consagrava: 1) o predomínio da dimensão educativa, face à assistencial; 2) a sua conceção como antecâmara da escola primária; 3) a definição de métodos próprios, diferentes daqueles utilizados com as crianças mais velhas, adequados às caraterísticas e às necessidades específicas destas idades; 4) e a definição da profissão de educador de infância como uma profissão exclusivamente feminina.

A preocupação centrada na função educativa, de sabor froebeliano, não logrou alterar as práticas sociais. Prevaleceu a função social sustentada numa narrativa que compaginava guarda com compensação de desigualdades do meio sociocultural familiar. A especificidade do jardim de infância estava longe de colher a unanimidade e a função de instrução era, muitas vezes, salientada. A legislação de 1894 convoca a expressão escola infantil em vez de jardim de infância e é recorrente, nas diversas peças legislativas, a referência ao ensino infantil (Vilarinho, 2000). De resto, este cunho escolarizante acentuou-se na produção legislativa do início do século dado que, embora se estipule que a educação de infância não é um grau de ensino, se valoriza o seu contributo na instrução das crianças, ao destacar o seu papel no desenvolvimento intelectual das crianças e na sua preparação para a entrada na escola primária, ainda que salvaguardando a consideração pelas características e capacidades das crianças, bem como a conceção da infância como processo de maturação (Cardona, 1997).

Sentido normativo que, neste arco temporal, conviveu com a crescente consensualização, entre os pedagogistas das propostas de Friedrich Froebel, ainda que sem grande expressão pública. Remonta a meados do século XIx a publicação do primeiro artigo sobre o pedagogo alemão em Portugal,

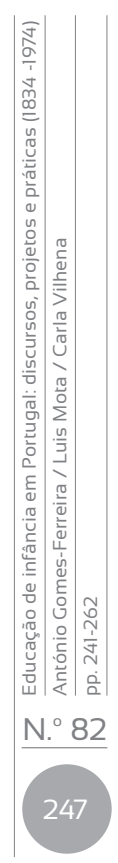


intitulado "Frederico Froebel - Jardins-de-infância", assinado por Luís Filipe Leite. Contudo, só cerca de duas décadas depois voltamos a detetar a presença ideológica de Froebel, aquando da utilização de materiais e exercícios froebelianos na educação de crianças, no Porto, por Francisco Adolfo Coelho (Fernandes, 2004). Assistiu-se, nas décadas seguintes, à divulgação da obra e dos métodos do pedagogo alemão nas páginas da imprensa (e.g., Menezes, 1882; Froebel e os jardins de infância, 1885; Eunes, 1904), sobrelevando o facto de este ter criado um método e um conjunto de materiais didáticos adequados à educação das crianças mais pequenas (Raposo, 1882). Já na cidade invicta, a Sociedade de Instrução do Porto (1880), composta por um conjunto de interessados na "coisa" da educação, adquire um conjunto de material pedagógico froebeliano, promove conferências e exposições e encontra acolhimento para a sua sugestão de enviar bolseiras ao estrangeiro em formação.

Enfatize-se, a par de Carolina Michäellis, Joaquim António de Vasconcelos, Adolfo Coelho e Bernardino Machado, a atividade do pedagogo José Augusto Coelho (1850-1925), professor do ensino normal primário, autor de manuais de pedagogia e metodologia educativa, influenciado pelo evolucionismo de raiz spenceriana e representante dos pedagogistas Pestalozzi e Froebel, elabora um programa para uma escola infantil, destinada a crianças entre os quatro e os oito anos de idade. Mobilizando uma conceção cientificista do conhecimento, compagina uma definição de idades (fases da vida educativa) com um conjunto de saberes, psicológicos e pedagógicos, sustentando uma escola infantil dividida em quatro períodos, sistematizando um conjunto de propostas práticas, recorrendo ao método intuitivo e às lições de coisas (Ferreira, et al., 2019).

Ações que se filiam num conjunto de ideias inovadoras no domínio filosófico, social e histórico que perpassam pelo continente europeu e que compaginam a ideia de renovação cultural com estoutra de reforma pedagógica. É, de resto, conhecida a presença e circulação de educadores portugueses em instituições educativas europeias, de que resulta a sua intervenção no sistema escolar português (Ferreira, et al., 2019).

Já em pleno século xx, a Associação de Escolas Móveis pelo Método de João de Deus, criada igualmente no início da década de oitenta do século XIX, altera os seus estatutos passando a designar-se por Associação de Escolas Móveis pelo Método João de Deus, Bibliotecas Ambulantes e Jardins-Escolas (1907), propondo-se instituir jardins-escolas, para crianças dos três aos sete anos de idade, enquadrados na obra educativa de João de Deus. Iniciativa com um significado incontornável no domínio da educação das crianças mais pequenas, que atravessa todo o século xx e, ainda hoje, constitui uma oferta educativa diferenciada, na formação social portuguesa, para as crianças daquela faixa etária. 


\section{No campo das intenções ou a construção retórica da escolarização da infância}

A preocupação inequívoca com a educação das primeiras idades, bem expressa nos discursos e nas diversas iniciativas sociais e legislativas —e.g., Hintze Ribeiro (1901)_ que desembocaria, nos primeiros anos de regime republicano, na criação do ensino infantil oficial e em formação de professores especializados na educação de crianças dos 4 aos 7 anos de idade, pouco mais representou do que manifestação de intenções.

A crença na educação como móbil da regeneração do país e esteio para a construção de um homem novo, liberto dos dogmas do passado, por via do desenvolvimento moral e intelectual dos cidadãos, agentes ativos na transformação social (Candeias, 2006; Ferreira, 2014), coloca a educação, em geral, e a educação da infância, em particular, no centro da agenda política, num tempo em que ganhava visibilidade a importância de afastar as crianças de ambientes nocivos —e.g., a rua como espaço de contágio e de todos os vícios - , bem como das mãos das ("ignorantes" e "incapazes") mães que, desconhecedoras dos princípios científicos de criação e educação das crianças, não se encontravam em condições de dispensarem aos seus filhos uma educação racional e positiva (Serpa, 1913).

Não admira, por isso, que logo em 1910 o governo provisório tenha determinado que a cerca adjacente ao Palácio das Necessidades e as suas dependências rurais, passassem a denominar-se Jardim Infantil, recaindo na inspeção escolar da capital a apresentação do respetivo plano de adequação. Nesse mesmo ano, constitui-se uma comissão para preparar a reforma do sistema educativo, integrada por nomes como João de Barros ou João de Deus Ramos, que organizaria o sistema de ensino primário em três níveis, contemplando o ensino infantil —perspetivado como pré-primária e como parte integrante do sistema educativo-, para as crianças dos três aos sete anos e sustentando a "nacionalização" da escola infantil pela via da universalização do método João de Deus.

As propostas da comissão foram objeto de reconsideração, pelo poder político, antes de serem vertidas para normativo legal. A lei da educação republicana consagraria um ensino infantil facultativo e gratuito com a finalidade de promover a educação e o desenvolvimento integral das crianças dos 4 aos 7 anos de idade, compaginando uma definição em função das aprendizagens escolares visível no currículo - e.g., preliminares de leitura e escrita, noções de geografia descritiva ou soma e subtração- com especificidades associadas a este nível etário, ao nível do método e dos materiais (Ministério da Instrução, 1911b), traduzindo uma certa tensão nas funções cometidas ao ensino infantil com expressão na procura do equilíbrio entre o pendor escolarizante e uma natureza desenvolvimentista. Em linha com o disposto, o "programa das escolas 
infantis" identificava como missão destas escolas realizar a transição da família para a escola primária, promovendo o desenvolvimento integral da criança, não deixando de sublinhar a importância da educação de infância para a futura vida escolar e acautelando a duração reduzida das lições, focadas nos interesses da criança e com recurso a processos de ensino exclusivamente intuitivos (Ministério da Instrução, 1911a). As escolas infantis, na perspetiva do inspetor escolar Heitor Passos (1921), organizadas e norteadas pelos princípios da pedagogia e da psicologia, cumpririam tal desiderato.

Para a formação de docentes, o legislador determinou um curso de formação de professoras do ensino primário, a obter nas escolas normais primárias, e a frequência de um curso específico para o ensino em escolas infantis com a duração de dois anos. Na ausência de colaboradoras, para usar uma expressão atual, qualificadas, a lei prevê o recrutamento de professoras primárias com bom e efetivo serviço (Ministério da Instrução, 1911b). A acuidade de uma educação da criança fundada no conhecimento científico que vinha sendo produzido sobre o desenvolvimento da criança, contribuiu para a atenção dedicada à formação de profissionais para a educação de infância, assinalando-se a necessidade e a importância das futuras "jardineiras" conhecerem os princípios de Pestalozzi e de Froebel, bem como das leis que presidiam ao desenvolvimento psíquico e fisiológico da criança (Cardoso Jr., 1922). De resto, os próprios programas das escolas normais primárias traduziam esta preocupação, revelando uma atenção particular ao ensino de metodologias específicas compaginadas com os avanços científicos e adequadas ao conhecimento da criança, aspeto essencial para a adequação da ação educativa ao seu nível de desenvolvimento —e.g., Pedologia (Ministério da Instrução, 1924).

A labuta legislativa foi intensa para 16 anos de vigência da Primeira República. Já após a I Grande Guerra, Leonardo Coimbra promove uma reforma integrando o ensino infantil no ensino primário (Ministério da Instrução, 1919) que passava assim a possuir três graus: infantil, primário geral e primário superior. Em 1922, dois diplomas que regulamentavam horários e calendários escolares (Ministério da Instrução, 1922b; Ministério da Instrução, 1922a), embora considerassem a idade das crianças, colocavam a escola infantil ao nível das demais. O legislador não se quedaria por aspetos organizativos, orientando a sua intervenção também sobre o currículo, refletindo preocupação em promover valores de cidadania e uma educação integral e laica, refletindo a influência do "movimento" de Educação Nova.

A realidade é que, apesar da retórica normativo-legal, o ensino infantil público permaneceu quase inexistente e a década que se inicia com a ditadura militar em 28 de maio de 1926, não altera, nem quanto à substância, nem quanto à forma, o status quo. Durante a vigência da Primeira 
República registam-se a entrada em funcionamento de doze escolas infantis, sem esquecer que uma ou outra coletividade/ instituição possam ter mantido alguma escola infantil, mas incluindo, neste balanço, a escola israelita e os jardins-escola João de Deus. Em 1927, o anuário estatístico regista 55 "escolas e secções de ensino infantil", não se devendo perder de vista que estas secções infantis, criadas por Leonardo Jardim (1919), se destinavam a crianças entre os 6 e os 7 anos. Na década que se inicia em 1926-1927 não se registam alterações significativas, seja no número de escolas ou secções, de educadoras, de crianças ou na sua distribuição geográfica (Ferreira et al., 2019).

A profusa legislação e a dececionante capacidade de concretização, não retiram o mérito, aos governantes da I República, do reconhecimento da função educativa da educação de infância e da sua integração no sistema educativo (Vilarinho, 2000). Semelhante incapacidade pode convocar diferentes explicações, desde logo, a ausência de uma estratégia, por parte da elite política republicana, perante uma situação (quase) caótica - $75 \%$ de analfabetos e $17,5 \%$ das paróquias sem escola primária, a que se associa a grave instabilidade política (46 governos em 16 anos) e a débil situação económica. Ainda assim o entusiasmo e a abertura do debate educativo, em geral, e sobre a educação de infância, em particular, estimulou a reflexão pedagógica e iniciativas privadas, de que é exemplo a Associação João de Deus.

Com a crescente divulgação de conhecimentos pedagógicos e didáticos, de raiz científica, a pedagogia científica foi-se progressivamente afirmando e outros autores começavam a disputar a hegemonia ao pensamento de Froebel —e.g., a câmara municipal de Lisboa, em 1916, envia uma missão de professores primários ao Curso Internacional de Pedagogia de Maria Montessori, em Barcelona. A influência de Maria Montessori acentuou-se, particularmente, por influência de António Sérgio (1883-1969), cujo contributo para a educação, o pensador português considerava relevante. Sérgio também dedicou algumas das suas reflexões à educação de infância e à sua caracterização, defendendo que a educação deveria partir dos interesses da criança em articulação com as características socioculturais da comunidade. Propunha um ensino cooperativo que possibilitasse o desenvolvimento da autonomia e do espírito crítico. Na perspetiva organizacional pugnava pela criação de comunidades educativas, possuidoras de vida social própria, constituindo uma aprendizagem pela prática da democracia.

Significativos, ainda, os contributos de Adelaide Cabete (1867-1935), Irene Lisboa (1892-1958) e Ilda Moreira (1849-1980), referenciadoas a partir do texto de Vasconcelos (2004). A primeira, já durante a ditadura militar, instada pela mortalidade infantil, publica "O ensino da puericultura na escola infantil" (1928), perspetivando a educação de infância pela sua

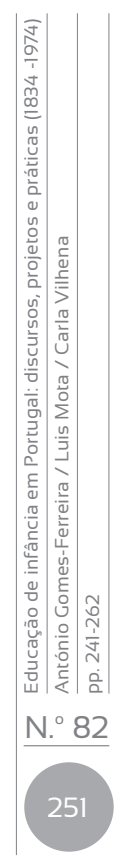


vertente de prevenção social. Já Irene Lisboa, pelo seu lado, apresenta uma proposta de "Bases para um programa de escola infantil" (1933), que apelidava de "A Escola Atraente", introduzindo ideias e práticas do movimento da Educação Nova, explicitando as especificidades da educação de infância, esbatendo o crescente caráter de preparação para a escola primária, conferindo prioridade à expansão dos interesses da criança. Por último, o contributo de Ilda Moreira, que criou as escolas infantis oficiais da Tapada da Ajuda, ensaiando novas modalidades de ensino infantil marcadas pelas ideias de Maria Montessori e Ovide Decroly (Vasconcelos, 2004). Na mesma escala de atuação, gorada que foi a hipótese da adoção como modelo nacional o seu método educativo, a Associação João de Deus norteou-se na prossecução de um dos objetivos definidos nos estatutos de 1908: instituir Jardins-Escolas. À data da instauração do Estado Novo já tinha em funcionamento cinco jardins-escola.

\section{A ideologia da maternidade e a natureza assistencial e privada da educação de infância}

O tempo de afirmação da função educativa do ensino infantil e da sua integração no sistema oficial de educação acabara porque a nova Constituição (1933) encerrava uma outra filosofia. A convicção ideológica do Estado Novo iria, agora, concretizar-se de forma (quase) hegemónica na educação com o consulado de Carneiro Pacheco (1887-1957), entre 1936 e 1940, e significativamente sublinhada com a mudança de designação do Ministério da Instução para Ministério da Educação Nacional (1936).

Adotando a perspetiva da família como núcleo da organização social, a nova política confere à mulher o espaço privado doméstico e atribui a responsabilidade de educação das crianças à família. No seio desta, exibindo uma idealização da maternidade muito tradicional, a incumbência recai sobre a mulher, considerada esteio da família e da ordem social (Ministério da Educação Nacional, 1936).

É na prossecução deste desiderato que ocorre a institucionalização da Obra das Mães para a Educação Nacional (OMEN), organização estatal feminina, visando a educação integral das mulheres, promovendo a habilitação das mães para a educação familiar, nomeadamente, para o exercício da função de educadoras dos seus filhos. A OMEN propunha-se incentivar a ação educativa da família e promover e assegurar a educação infantil pré-escolar, em complemento da ação da família (Ministério da Educação Nacional, 1936).

A preocupação com a preparação das mães para a realização desta tarefa denota a prevalência da ideologia da maternidade científica, evidenciando a crença de que os comportamentos maternais devem ter por base o 
conhecimento proveniente da ciência. Os discursos acerca da necessidade de proteção à infância pobre, quer através da frequência de instituições de educação de infância, quer através da educação das mães das classes populares, têm subjacente uma preocupação higienista com o combate à mortalidade e morbilidade infantis, pugnando por assistência infantil em moldes científicos (Sousa, 1939). As instituições de educação de infância são assim entendidas como parte de um dispositivo mais vasto de assistência à maternidade e à infância que englobava um conjunto diversificado de instituições, tais como dispensários de puericultura, lactários ou creches, cuja finalidade era não só assegurar a constituição de corpos robustos, mas também, de almas sãs (Souto, 1933). A maioria das instituições referidas neste período - e.g. Lar do Pequeninos, em Montemor-o-Novo (Noticiário: 'Lar dos Pequeninos', 1941), Centro Maternal e Infantil (Fundação Júlia Moreira) ou a Creche de Pedro Folque (Os amigos das crianças, 1945) inserem-se nesta lógica assistencial de proteção à maternidade e à infância.

Em 1937 o ensino oficial infantil foi definitivamente extinto, sob o pretexto da impossibilidade de o assegurar a todas as crianças do país (Ministério da Educação Nacional, 1937), cometendo-se ao Estado o estimular a ação educativa da família, auxiliar as instituições particulares que promovessem a educação pré-escolar e exercer a função de regulador ou supervisor. Prevalece, como orientação, e em prejuízo da função educativa, o caráter assistencial e de resposta às questões sociofamiliares que afetam a vida das crianças, assumindo um papel de vigilância das classes populares. Sinal dessa orientação, o ensino da infância transita do Ministério da Educação Nacional (MEN) para a subsecretaria de Estado da Assistência Social, sob tutela do Ministério do Interior, posteriormente elevada a ministério.

O paradigma enquadrou a formação das educadoras e auxiliares configurando-a no quadro do ensino particular e no plano assistencial. A Escola Normal Social, criada no segundo lustro da década de trinta, estabelecimento de ensino particular e dedicada à formação de assistentes sociais, com um currículo orientado para obras de assistência materno-infantil, criaria um curso de especialização em enfermeiras puericultoras visitadoras da infância com competências de educadora de infância (Ferreira e Mota, 2018).

A tendência para a centralização e privatização dos serviços assistência social (Cardona, 1997) acentuou-se, ilustrada nas suas bases reguladoras (Ministério da Educação Nacional, 1944). Em 1945 são criados um conjunto de institutos, orientados para amparo e educação de jovens, e o Instituto de Assistência à Família, responsável pela criação de estabelecimentos de ensino e serviços de assistência infantil (Ministério da Educação Nacional, 1945). A ideia não vingou, desde logo, por omissão estatal no apoio financeiro. Já em 1949 e no quadro do MEN, aquando da definição do Estatuto do Ensino Particular (Ministério da Educação Nacional, 1949), o ensino infantil é definido para as crianças sem idade escolar, elencam-se critérios para a 
abertura de estabelecimentos e especificam-se a idoneidade moral e cívica, bem como a preparação especializada, enquanto critérios exigidos para os seus recursos humanos.

No quadro da educação infantil foram sobrevivendo certas iniciativas, especialmente, no âmbito da assistência social. Destaque-se a ação desenvolvida por Bissaya Barreto, no seio da Obra de Proteção à Grávida e Defesa da Criança (OPGDC), procurando encontrar resposta às carências sociais de famílias e crianças, criando as Casas da Criança, configuradas pelo modelo pedagógico de Maria de Montessori, cuja influência transparece no próprio nome, com valência de creche e de jardim de infância. De 1936 a 1970, foram criadas 25 Casas da Criança na região centro de Portugal (Ferreira e Mota, 2018).

Releve-se, ainda, a continuidade da ação da Associação de Escolas Móveis e Jardins-Escolas João de Deus, de iniciativa privada e com função educativa, promovendo a generalização de um "modelo português de escola infantil", norteado pelas conceções da Cartilha Maternal. Em 1946, adotou a designação de Associação de Jardins-Escolas João de Deus. Definido estatutariamente, passam a realizar, com caráter anual e a duração de dois anos (mais tarde, três), um curso de didática pré-primária para habilitação ao magistério do ensino infantil. Em abril de 1974 existiam 23 Jardins-Escola João de Deus e, em cerca de três décadas, a Associação tinha formado 1118 educadoras (Gomes, 1977).

Em síntese, marcada pela privatização e pelo pendor assistencialista, a educação de infância parece desenvolver-se em dois eixos socialmente diferenciados, por um lado, atualiza-se em instituições de cariz privado, destinadas a crianças de meios sociais favorecidos, predominando as preocupações educativas, e, por outro, instituições de natureza e caráter assistencialista (com exceções), destinadas a filhos de mães trabalhadoras, frequentadas por crianças provenientes de meios socialmente desfavorecidos (Santos, 1953).

\section{A educação de infância nos anos de viragem}

Os anos 50 e 60 encerram transformações na sociedade portuguesa com repercussões várias, nomeadamente, ao nível da educação pré-escolar. A formação social portuguesa, apesar da continuação do regime do Estado Novo, vivenciaria, nas décadas subsequentes a 1945, um tempo de "mudanças invisíveis" (Rosas, 1994), com sentido de transformação estrutural entre 1950 e 1974, especialmente acentuado com o avançar da década de sessenta. Alterações na estrutura económica, decorrente do crescimento industrial, o acentuar da terciarização, a guerra colonial e a emigração, provocou um aumento da taxa de trabalho feminino. A entrada de mais mães no mercado 
de trabalho traduz-se numa maior procura social da guarda das crianças. À semelhança de outros países da Comunidade Europeia, também em Portugal o crescimento da taxa de trabalho feminino explica a expansão das creches e jardins-de-infância (Vilarinho, 2000).

Entre os anos cinquenta e setenta, o panorama da educação infantil vai transformando-se paulatinamente, crescendo o número de estabelecimentos de educação infantil e o de crianças a frequentar a educação de infância, bem como o número de instituições normais de educação de infância. Os estabelecimentos de educação infantil passaram de 94, em 1950-1951, para 177, em 1959-1960, e 209, em 1962-1963, correspondendo a um aumento de trinta e duas instituições, representando um crescimento da oferta de cerca de $18 \%$. No mesmo período, das 1954 crianças a frequentarem estabelecimentos de educação infantil passou-se para seis mil, em 1959-1960, e mais de oito mil, em 1962-1963.

De igual modo, alargou-se a oferta de instituições normais de educação de infância. Assim, em 1954, foram criadas duas escolas particulares de educadoras de infância, o Instituto de Educação Infantil, criado pela Associação de Educação Infantil, e a Associação de Pedagogia Infantil criou a Escola de Educadoras de Infância. Adotando como elementos estruturantes, para a formação das educadoras, o espírito de apostolado e de missão e a moral católica (Vilarinho, 2000), mobilizam uma conceção educativa centrada na criança, convocando os preceitos emanados das ciências da infância, muito especialmente, os oriundos da psicologia infantil. Em 1963, duas escolas dependentes da Inspeção-geral do Ensino Particular, em Coimbra, a Escola de Educadoras de Infância de Nossa Senhora da Anunciação, criada pelo Instituto Servas do Apostolado — funcionaria entre 1955 e 1974-, e no Porto, de iniciativa das irmãs doroteias, a Escola de Educadoras Paula Franssinetti. Quatro anos mais tarde, na dependência da Direcção-Geral da Assistência, são criadas, no Porto e em Lisboa, duas escolas de auxiliares de educação de infância. Em 1968, por acordo entre a Direcção-Geral da Assistência, o Instituto das Irmãs de Santa Doroteia e o Patronato de Santa Doroteia, começa a funcionar a Escola Paulo vı, com o objetivo de preparar profissionalmente educadoras e auxiliares de educação, dos estabelecimentos de assistência a menores (Ferreira et al., 2019).

Os anos sessenta do século xx constituem, assim, para a educação de infância formal, um momento de viragem. As transformações que ocorrem na política educativa portuguesa, fruto de uma preocupação crescente com a formação de recursos humanos para o desenvolvimento económico (Teodoro, 2001), o aumento da taxa de emprego feminino e o consequente aumento da procura social de locais de acolhimento das crianças mais pequenas (Vilarinho, 2000), a divulgação de estudos que evidenciam a função compensatória da educação de infância, ou seja, o seu papel no combate ao insucesso escolar, sobretudo entre as crianças das classes 
mais desfavorecidas, são alguns dos fatores que contribuem não só para que se olhe com outros olhos para a educação de infância, mas também que se inicie, embora de uma forma ainda muito incipiente, a construção da rede pública de educação pré-escolar (Nóvoa, 2005), tornada quase uma necessidade pela procura crescente deste nível educativo que, entre 1960 e 1965, quase triplicou (Sampaio, 1968).

O papel atribuído à educação de infância formal na promoção da saúde mental, na compensação das deficiências na educação familiar, quer por incapacidade dos pais, quer pelo número crescente de mães trabalhadoras, a "maior facilidade de adaptação ao ensino primário das crianças que frequentaram o ensino infantil" (Sampaio, 1968, p. 86), são motivos invocados para a necessidade de expandir o ensino infantil.

De algum modo, também terá contribuído para essa evolução a participação de Portugal no 'Projeto Regional do Mediterrâneo', coordenado pela Organização de Cooperação e Desenvolvimento Económicos (OCDE), que imprime novos sentidos às políticas económicas e sociais as quais passaram a estar ligadas ao desenvolvimento do sector da educação escolar, o que vai, efetivamente, promover uma notável expansão, qualitativa e quantitativa, do sistema de ensino, particularmente nas décadas de 60 e 70. Objeto de dois relatórios (Instituto de Alta Cultura, 1963; 1964), o primeiro, apresenta a situação da educação de infância à época, caracterizando-a como dependente de instituições privadas, exclusivamente urbana e com custos mensais elevados por criança para as famílias. O segundo relatório, apresenta uma previsão para 24 mil crianças inscritas, na educação de infância, em 1974-1975, advertindo, no entanto, para as dificuldades de previsão face à irregularidade de crescimento do ensino infantil, em Portugal, bem como é destacado o elevado ratio entre crianças e educador.

As preocupações relativas à educação de infância retomam, na sua função compensatória, preventiva e a par da formação de educadoras, alguma visibilidade num relatório (1964) dirigido por Émile Planchard, o qual tinha como objetivo a organização de um novo Estatuto da Educação Nacional, onde se propõe a necessidade de preparar uma rede oficial de jardins de infância e de criação de escolas públicas para a formação de educadoras (Cardona, 1997). De resto, um parecer da Câmara Corporativa sobre Ensino e Investigação, aquando da discussão do Plano Intercalar de Fomento para 1965-1967, articulando a dimensão da educação infantil em Portugal, as limitações das famílias na sua concretização e a sua importância no desenvolvimento da criança, recomenda a criação oficial do ensino infantil (Gomes, 1977).

Ao nível dos discursos oficiais, até 1973, as orientações para a educação pré-escolar seguem os princípios antes referidos. Nesse mesmo ano, antes da reforma do sistema educativo, é criada no Ministério da Educação 
Nacional, a Divisão de Educação Pré-Escolar (DEPE). Em julho, a reforma de Veiga Simão confere um novo impulso a este percurso ao reintegrar a educação infantil no sistema educativo, atribuindo-lhe o desígnio do desenvolvimento global e harmonioso da criança, mas sem esquecer a preocupação com os princípios morais e religiosos (Ministério da Educação Nacional, 1973).

A preocupação com efetividade da lei manifesta-se, desde logo, com a criação de duas escolas do magistério infantil (despacho ministerial de 20 de junho) ainda antes da promulgação da Lei 5/73, uma em Coimbra e outra em Viana do Castelo, iniciando funções, respetivamente, em novembro e dezembro de 1973, sendo também criados vários jardins infantis, em serviços dependentes do Ministério da Educação Nacional (Gomes, 1977). Contudo, como denunciou Salvado Sampaio, a natureza de experiência e o seu limitado âmbito, não permitiu criar condições reais e objetivas de expansão e democratização da educação pré-escolar.

\section{Conclusões}

O desenvolvimento da educação de infância, no espaço europeu, foi um processo lento e desigual, atendendo aos contrastes regionais, às profundas assimetrias socioeconómicas e em face de diversas composições sociais e culturais de que resultaram diferenciadas apropriações das ideias sobre a educação das crianças e distintos posicionamentos sobre a assunção da infância. As condições materiais e simbólicas de existência configuraram o desenvolvimento da educação das crianças e a assunção da infância em Portugal.

No período de 1834 a 1910, a produção legislativa compaginou-se com valorização da função educativa das instituições, contudo os resultados foram insignificantes. A despeito da preocupação de pedagogos e políticos, o ensino infantil enfrentava a incapacidade do Estado em concretizar um projeto significativo no âmbito do sistema educativo, sendo sucessivamente adiado. Só no ano do centenário do nascimento de Friedrich Froebel foi possível inaugurar em Lisboa, no jardim da Estrela, o primeiro jardim de infância público, influenciado pelo método froebeliano.

A crença na educação como móbil da regeneração do país e esteio para a construção de um homem novo, liberto dos dogmas do passado, por via do desenvolvimento moral e intelectual dos cidadãos, colocou a educação, em geral, e a educação da infância, em particular, no centro da agenda política durante a Primeira República. A realidade é que, apesar da retórica normativo-legal, o ensino infantil público permaneceu quase inexistente e a década que se iniciou com a ditadura militar em 28 de maio de 1926, não alterou, nem quanto à substância, nem quanto à forma, o status 
quo. Releve-se, ainda assim, que a Primeira República constituiu um tempo de afirmação da função educativa do ensino infantil e da sua integração no sistema oficial de educação.

A legitimidade política do Estado Novo concretizou-se de forma hegemónica na educação, com o consulado de Carneiro Pacheco (1887-1957), entre 1936 e 1940, e significativamente sublinhada com a mudança de designação para Ministério da Educação Nacional (1936).

Marcado pela ideologia da família como núcleo da organização social, o Estado Novoconfere à mulher o espaço privado doméstico e atribuiu a responsabilidade de educação das crianças à família. No seio desta, exibindo uma idealização da maternidade muito tradicional, a incumbência recaiu sobre a mulher.

Em síntese, marcada pela privatização e pelo pendor assistencialista, a educação de infância atualizou-se em dois eixos socialmente diferenciados, por um lado, atualiza-se em instituições de cariz privado, destinadas a crianças de meios sociais favorecidos, predominando as preocupações educativas, e, por outro, instituições de natureza e caráter assistencialista, destinadas a filhos de mães trabalhadoras, frequentadas por crianças provenientes de meios socialmente desfavorecidos.

Durante os anos que considerámos de viragem, nas décadas de sessenta e no primeiro lustro da década de 70 verificou-se que, apesar das intenções políticas, constata-se a quase ausência de educação infantil. A educação pré-escolar, neste mesmo período, circunscreve-se sobretudo aos centros urbanos, onde a densidade populacional, sendo mais elevada, é indicadora do consequente desenvolvimento dos sectores comercial e industrial. Poder-se-á ainda inferir que nas cidades onde a população é predominantemente rural, a procura social dos jardins-de-infância está associada ao aumento de trabalho feminino.

Da visão assistencialista e moralizadora, que marcou a política do Estado Novo até 1970, emergiram duas vias para o desenvolvimento de serviços de apoio à criança: uma de essência social e solidária e uma outra de natureza predominantemente educativa (a partir de 1973), sob a responsabilidade do Ministério da Educação Nacional e a partir da reforma do Sistema Educativo.

\section{Referências}

Beatty, B. (1995). Preschool education in America: The culture of young children from the colonial era to the present. Yale University Press.

Beatty, B., Cahan, E. D. e Grant, J. (Eds.) (2006). When science encounters the child: Education, parenting, and child welfare in 20th-century America. Teachers College Press. 
Boto, C. (2001). A civilização escolar como projeto político e pedagógico da modernidade: Cultura em classes, por escrito. Cadernos CEDES, 23(61), 378-397.

Brehony, K. (2009). Transforming theories of childhood and early childhood education: Child study and the empirical assault on Froebelian rationalism. Paedagogica Historica, 45(4/5), 585-604.

Candeias, A. (2006). Inovação, rutura e continuidade na $1^{\text {a }}$ República: Um balanço crítico sobre a educação. Revista da Faculdade de Ciências Humanas e Sociais, 18, 211-231.

Cardona, M. J. (1997). Para a história da educação de infância em Portugal: O discurso oficial (1834-1990). Porto Editora.

Cardoso Jr. (1922). Ensino infantil. Revista Escolar, 2(11), 305-306.

Cunningham, H. (1995). Children and childhood in western society since 1500. Pearson Education.

Dombkowski, K. (2001). Will the real kindergarten please stand up? Defining and redefining the twentieth-century US kindergarten. History of Education, 30(6), 527-545.

Eunes, G. (1904). Palestra higiénica: Os amigos das crianças: A escola. Revista Pedagógica, ı(15), 229-232.

Fernandes, R. (2004). Roturas e permanências da educação portuguesa no século xıx. História da Educação, 15, 7-27.

Ferreira, A. G. (1988). Três propostas pedagógicas de finais de Seiscentos: Gusmão, Fénelon e Locke. Revista Portuguesa de Pedagogia, XXII, $267-292$.

Ferreira, A. G. (2000). Gerar, Criar, Educar. A criança no Portugal do Antigo Regime. Quarteto.

Ferreira, A. G. (2014). A criança e a pedologia no contexto da $1^{\text {a }}$ República. Em: A. Mourão e A. C. Gomes (Eds.), A experiência da Primeira República no Brasil e em Portugal. Imprensa da Universidade de Coimbra.

Ferreira, A. G. e Gondra, J. (2006). Idades da vida, infância e a racionalidade médico-higiênica em Portugal e no Brasil (séculos 17-19). Revista Brasileira de Estudos Pedagógicos, 87(216), 119-134.

Ferreira, A. G. e Mota, L. (2018). "Cada Casa da Criança que se abre, corresponde a uma enfermaria que se fecha": Gerar, criar e educar no Estado Novo. Sarmiento. Revista Galego-Portuguesa de História da Educación, 22, 133-152.

Ferreira, A. G. e Pereira, A. P. (1987). Um relance sobre a criança no século xvı. Revista Portuguesa de Pedagogia. Ano Xxı, 168-198.

Ferreira, A. G., Mota, L. e Vilhena, C. (2019). A educação de infância em Portugal. Em: A. G. Ferreira, e L. Mota. (Coord.). Caminhos da educação da Infância em Portugal: políticas e perspetivas contemporâneas. (pp. 17-76). De Facto Editores. 
Ferreira, T. (1882). Escolas infantis ou jardins de Froebel: Apontamentos para a sua história em Portugal. Froebel, ı(1), 2-3.

Froebel e os jardins de infância (1885). O Ensino, II(9), 135-140.

Gomes, J. F. (1977). A educação infantil em Portugal. Almedina.

Hendrick, H. (1997). Constructions and reconstructions of British childhood: An interpretative survey, 1800 to the the present. Em A. James e A. Prout (Eds.), Constructing and reconstructing childhood (pp. 34-62). Falmer Press.

Hofstetter, R. (2012). Le transformation de I'enfant en écolier (du 19e au milieu du 20e siècle): Les "eurêkas" des sciences de l'homme naissantes, entre scientisme et romantisme: un "naturalisme" de l'enfance. Paedagogica Historica, 48(1), 31-50.

Instituto de Alta Cultura. (1963). Projecto Regional do Mediterrâneo. Análise quantitativa da estrutura escolar portuguesa, 1950-1959. IAC

Instituto de Alta Cultura. (1964). Projecto Regional do Mediterrâneo. Evolução da estrutura escolar portuguesa (Metrópole) - previsão para 1975. IAC

Lopes, M. A. (1993). Os pobres e a assistência pública. Em: J. Mattoso (Series Ed.), L. R. Torgal e J. Roque (Vol. Eds.), História de Portugal: Vol. 5. O Liberalismo (pp. 501 - 515). Círculo de Leitores.

Luc, J. N. (1997). L'invention du jeune enfant au xix siècle: De la salle d'asile à l'école maternelle. Paris: Belin.

Menezes, H. T. (1882). Sem título. Froebel, ı(1), 3.

Ministério da Educação Nacional. (1936). Decreto n. ${ }^{\circ}$ 26893/1936. Diário do Governo. I Série, 191, pp. 981-984.

Ministério da Educação Nacional. (1937). Decreto-lei n. ${ }^{o}$ 28081/1937. Diário de Governo. I Série, 236, pp. 1071-1073.

Ministério da Educação Nacional. (1944). Lei n. ${ }^{0}$ 1998/1944. Diário de Governo. I Série, 102, pp. 433-437.

Ministério da Educação Nacional. (1945). Decreto lei n. ${ }^{o}$ 35108/1945. Diário de Governo. । Série, 247, pp. 899-922.

Ministério da Educação Nacional. (1949). Decreto n. ${ }^{\circ} 37545 / 1949$. Diário de Governo. I Série, 197, pp. 654-662.

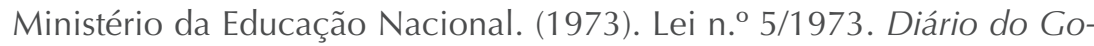
verno. I Série, 173, pp. 1315-1321.

Ministério da Instrução. (1911a). Decreto de 23 de agosto de 1911. Diário de Governo. 198, pp. 3597-3599.

Ministério da Instrução. (1911b). Decreto de 29 de março de 1911. Diário de Governo. 73, pp. 1841-1848.

Ministério da Instrução. (1919). Decreto n. ${ }^{\circ}$ 5787-B/1919. Diário de Governo. I Série, 93, pp. 1346-G - 1346-N. 
Ministério da Instrução. (1922a). Decreto n. ${ }^{\circ}$ 8203/1922. Diário de Governo. I Série, 121, pp. 584-585.

Ministério da Instrução. (1922b). Lei n. ${ }^{0}$ 1264/1922. Diário de Governo. I série, 89, p. 456.

Ministério da Instrução. (1924). Decreto n. ${ }^{0}$ 10219/1924. Diário de Governo. I Série, 240, pp. 1552-1558.

Nery, A. C. B. (2006). Periódicos educacionais portugueses: Circulação e apropriação de modelos culturais. Cadernos de História da Educação, 5, 73-82.

Noticiário: 'Lar dos Pequeninos' (1941). Revista Portuguesa de Pediatria e Puericultura, IV(4), 188-189.

Nóvoa, A. (2005). Evidentemente: Histórias da educação. Edições ASA.

Ordenações Afonsinas. (s. d.) Livro I, Título xxvı: Dos Juizes Hordenairos, e cousas que a seus Officios perteencem. Instituto de História e Teoria das Ideias da Faculdade de Letras de Coimbra. http://www1.ci.uc. pt/ihti/proj/afonsinas/l1p171.htm

Os amigos das crianças: A creche de Pedro Folque (1945). Os Nossos Filhos, 2(33), 13.

Raposo, S. (1882). Os jardins d'infância de Froebel. Froebel, ı(1), 4-6.

Read, J. (2013). Bringing Froebel into London's infant schools: The reforming practice of two head teachers, Elizabeth Shaw and Frances Roe, from the 1890s to the 1930s. History of Education, 42(6), 745-764.

Rosas, F. (1994). O Estado Novo (1926-1974). Círculo de Leitores.

Sampaio, S. (1968). O ensino infantil em Portugal. Boletim Bibliográfico e Informativo do Centro de Investigação Pedagógica da Fundação Calouste Gulbenkian, 8, 76-105.

Santana, H. (1924). Algumas notas para a história das escolas infantis do Porto. Educação Social, I(13/14), 244-245.

Santos, B. S. (1990). O Estado e a Sociedade em Portugal (1974-1988). Edições Afrontamento.

Santos, M. T. (1953). Escolas infantis. Os Nossos Filhos, 6(129), 9.

Serpa, M. P. B. (1913). Escola infantil. Revista Pedagógica, 244, 1-2.

Sousa, C. S. (1939). Necessidades e deficiências da assistência infantil. Revista Portuguesa de Pediatria e Puericultura, ॥(5), 221-242.

Souto, A. M. (1933). Assistência infantil - Creches. Brotéria, xvı(1), 37-42.

Teodoro, A. (2001). A construção política da educação: Estado, mudança social e políticas educativas no Portugal contemporâneo. Afrontamento.

Vasconcelos, J. M. (1853). Coleção oficial da legislação portuguesa: Ano de 1852. Imprensa Nacional.

Vasconcelos, T. (2004). Das Casas de Asilo ao Projecto de Cidadania. Políticas de Expansão da Educação de Infância em Portugal. Edições ASA. 
Vilarinho, E. (2000). Políticas de Educação Pré-Escolar em Portugal (19771997). Instituto de Inovação Educacional.

White, L. A. (2002). Ideas and the welfare state: Explaining childcare policy development in Canada and the United States. Comparative Political Studies, 35(6), 713-743.

Whitescarver, J. e Cossentino, J. (2008). Montessori and the mainstream: A century of reform on the margins. The Teachers College Record, 110(12), 2571-2600.

Wollons, R. (Ed.) (2000). Kindergarten \& cultures: The global diffusion of an idea. Yale University Press. 